\title{
BLOOMING OF 3D TO 5D PRINTING TECHNOLOGY IN BIOMEDICAL ENGINEERING
}

\section{MANISH $^{1} \&$ DEEPTI KATIYAR ${ }^{2}$}

${ }^{1}$ Department of Electronics and Communication Engineering, ABES Engineering College, Ghaziabad, Uttar Pradesh, India ${ }^{2}$ Department of Pharmacognosy, KIET School of Pharmacy, KIET Group of Institutions, Ghaziabad, Uttar Pradesh, India

The aeon of $2 D$ printing has moved towards $3 D$ additive manufacturing to $4 D$ bioprinting which has now advanced to $5 D$ printing. These advanced techniques are widely being used in various streams of engineering and medical fields. 3D printing involves a procedure of fabricating three dimensional items through additive manufacturing, i.e., creating the substance by laying one layer over the other. In medical field, the $3 D$ printing utilizes the bioink (containing live cells and biomaterials) for creating the biological models. But these models exhibit the stationary conduct after their manufacture and also lack the stimulus responses. Thus, this led to development of $4 \mathrm{D}$ technologies which creates $3 D$ objects which are able to alter their shape and size with time on variation of some external impetus like pH, temperature, light, magnetic field \& electric field etc. Major $4 \mathrm{D}$ printing techniques are based on deformation of materials and maturation of engineered tissue constructs. $5 D$ printing permits the creation of $3 D$ object in five different angles towards top which leads to the formation of a tougher and curved layered object.
\end{abstract}

KEYWORDS: 3D Printing, 4D Bioprinting, 5D Printing and Healthcare

Received: May 16, 2020; Accepted: Jun 04, 2020; Published: Aug 01, 2020; Paper Id.: IJMPERDJUN2020569

\section{INTRODUCTION}

In the current era printing does not refer only to two dimensional (2D Printing) which means printing with ink and paper, but it has now moved towards three dimensional (3D) to four dimensional (4D) to five dimensional (5D) printing technologies. The history of 3D printing dates back to 1980's when in 1981, two additive techniques for manufacturing three dimensional plastic models were invented by Hideo Kodama of Nagoya Municipal Industrial Research Institute. As per United States GAO (Government Accountability Office), 3D printing includes 3D articles from the digital replica utilizing layer-by-layer process. Just by altering the digital imitation, the machine can design unlimited diverse commodities. 'Additive Manufacturing', 'Rapid Prototyping' and 'Solid Free Form Fabrication' are the other terms for 3D printing (Chhaya et al., 2015). 3D printing is a fascinating technique that provides the opportunity to fabricate the complex structures with varied shapes and geometries. Stereolithographic 3D Printing, Powder Based (PB) 3D printing, Selective Laser Sintering (SLS) 3D printing, Extrusion based (EXT) 3D Printing and Fused deposition modelling (FDM) 3D printing are the methods used for 3D printing technology. This is a well-recognized expertise in the field of engineering. Currently, the technique is also being utilized in medical practices such as, tissue regeneration (Pati et al., 2013), production of health equipment (Chung et al., 2014), implants (Water et al., 2015) and pharmaceutical dosage forms (Goyanes et al., 2013). Even though there are several uses and benefits of 3D printing yet the main drawback with this technology is that it considers the target to be steady and insensate. It assumes that once printed, the objects will always remain in the initial geometrical shape. According to Bin Gao et al., "3D printing technology is based on the assumption that the 
printed cells can rapidly form and assemble tissues through cell adhesion, cell sorting and cell fusion processes, and then start to synthesize the extracellular matrices, which will provide and maintain desirable geometrical shape and mechanical properties in the tissue" (Gao et al., 2016).

Thus to overcome the problem, '4D bioprinting' has evolved in which 'time' is amalgamated with 3D additive printing as the fourth dimension. Here the meaning of this new dimension is that how the living tissues develop gradually with time after being printed (Xu et al., 2011). Two types of 4D bioprinting techniques have been reported. The first one is 4D printing based on the deformation of materials which involves the use of 'smart' materials which are responsive substances with innate features which have the capability to transform or reshape themselves on receiving external stimuli. This approach is alike to self folding, assembly and disassembly (Yang et al., 2014). Liquid metals, lipids and polymers can also be printed with the developments in material science. Now even more complicated organs like heart (Weber, 2007) and liver (Ikegami and Maehara, 2013) can be printed using this technique. The second technique of 4D printing is centered on the development of engineered tissue constructs is established on the maturation of concocted tissue fabrications after printing. The printed micro tissue undergoes maturation through various procedures like cellular coating, self organization and matrix deposition to slowly create the effective tissue set ups with a particular time limit (Miller $e t$ al., 2012).

The upcoming 5D printing technique is an amalgamation of additive and subtractive strategy. In the opinion of MERL (Mitsubishi Electric Research Laboratories), a lot of scrutiny of the entity to be printed is required in advance in order to know that how the 5D fabricated material shall be utilized. As per Dr. William Yerazunis, this technology permits for the fabrication of a substance from a single point ascending upwards from five axes. This is the reason for numeral 5 given in 5D. The movement of the printer tip occurs in five divergent directions due to which the target entity also proceeds effectively over the stage. Such motions permit the printing from various directions which could not be accomplished with 3D printing. The concurrent inclinations allocate the printing top to track the trail of article's form and sketch. Finally, the printed items can be fashioned in arched laminar as an alternative of plane laminar. The finest application of the 5D printing is for multifaceted arrangements and depiction necessitating a bunch of robustness (Kumar $e t$ al., 2019). Reddy and Devi state that "Components which need to be strong in order to be functional in the industry and due to their requirement to comply with industry norms and safety requirements make 5D printing an important technological advancement. As an example, a concave cap, an item that could not be 3D printed because it needs a lot of fillers and support and its design is very complex. Whereas 5D printing makes it easy print due to the capability to print curved layers". The advancement in additive engineering has directed to the evolution of "Halo 5D Printer" which permit the rotation and pivoting of the items for creating the complicated representation for artistic or any profitable application. This needs a type of the projecting method in 3D printers to produce substance in "5axes: 3axis of movement and 2 rotational axes". Thus, the Ethereal squad could pool the additive and subtractive methods for creating an alternative with 5-axes assembly. The Advantages of this technology are that 5D printer can also be utilized for cutting malleable metals and even the substances such as nylon. It can also fabricate substances for the manufacturing ornaments and portions of car. Tougher complicated items can be created with less stuff (Reddy and Devi, 2018).

\section{APPLICATIONS OF 3D PRINTING}

\section{Education}

The current world of learning demands the usage of novel technologies. 3D printing is one these technologies. It helps the 
students to learn the advancements in the field of engineering and also assists them to understand that how 3D file can be transformed to 3D object. It also provides the opportunity to the students to themselves create and manipulate the objects with different geometries and to transform their ideas into the 3D objects. The students of University of AlabamaHuntsville in 2013 have used 3D printing to fabricate device which can sense fire which was attached to helicopter without pilot intended to notice the fires and gunshots in jungles (Technologies, 2011).

\section{Architecture}

The 3D fabricated representations of houses and additional arrangements aid in better visualization of the layout. This technique has helped to reduce the time and expenses required to create the models. Winsun, a Chinese company had created a apartment have five floors with dimension of 1,100 square meter (Cnet, 2015).

\section{Marine}

Javed Shaikh Mohammad, has reviewed the applicability of 3D printing in Oceanography and he has stated that the technique can be used for manufacturing of marine (under water or over-water) transport, fabrication of imitations of sea creatures to understand the concepts of biomechanics, locomotion and hydrodynamics. 3D printed replicas of coral reef have been utilized for restoring the damaged coral reefs (Mohammad, 2016).

\section{4. $\quad$ Aerospace}

3D printing is now used in aerospace sector also. It is used for manufacturing the complex geometric designs and multiplex shapes. This is an economical technique which saves a lot of time and material. Czech Aircraft Company, Evektor fabricates the lightweight aircraft and automotive parts by utilizing the technique of $3 \mathrm{D}$ printing saving around $80 \%$ of the manufacturing cost (Sculpteo, 2016).

\section{Robotics}

Even the micrometer architecture for robotic motility has been created by three dimensional printing technologies. It is utilized to create the superficially power-driven simulated micro paddlers. 'Bio-hybrid robots' are fabricated by integrating the mobile cells with printing substances. Such robots could work by swaying and contraction of cells (Stanton et al., 2015).

\section{Consumer Goods}

3D printing offers an exhilarating opportunity to customers to opt for the products of their choice. This technology provides the customers the items of their own color and dimensions like cases for electronic devices, supplementary parts for household items and bottle openers (Technologies, 2016).

\section{Textiles}

Korger et al., utilized Fused Deposition Modeling 3D printing technology on various thermoplastic printing materials accessible in market targeting on the flexible filaments like thermoplastic elastomers. Different types of woven fabrics were fabricated and then subjected to tests for adhesion such as abrasion resistance and separation force tests. The study concluded by the statement - "The main influencing factor can be attributed to the topography of the textile surface affected by the weave, roughness and hairiness offering form locking connections followed by the wettability of the textile surface by the molten polymer, which depends on the textile surface energy and can be specifically controlled by washing 
(designing), finishing or plasma treatment of the textile before the print" (Korger et al., 2016).

\section{Automotives}

With 3D printing, it has become very easy to manufacture the lighter and stronger spare parts of vehicles with complicated geometries. Now, there is no requirement of manufacturing the great amount of locomotive fragments at a time and stocking them. They can be just saved in digital 3D file and fabricated with 3D printer as per the customers need. Pattni in 2016 has reported about presentation of a 3D printed minute solitary seated electrical carriage during CEATEC 2016 (Japanese Consumer electronics show) manufactured by Honda Automakers (Pattni, 2016).

\section{Industrial Goods}

The Additive manufacturing is also very beneficial for producing the industrial goods. It provides an opportunity that each product can be designed according to the need. It supports in creating the novel product designs and giving a chance to designers to apply their creativity. A research on mass customization by Fogliatto et al., has shown that "Product customization potentially yields an increase in customers perceived product value and, thus, higher willingness to pay" (Fogliatto et al., 2012).

\section{Military}

Exactly like the other industries, additive manufacturing has also provided an exhilarating opportunity to the military and defense industry to design and manufacture the complex, effective and reliable tools that can be used for defense purpose. Solid Concepts - Texas Based Company has fabricated fully functional 3D printed automatic pistol (Model 1911) using Laser Sintering technology. Kharpal, 2014 reported "In 2013 December, British fighter jets flew for the first time using parts made from 3D printing. Components including protecting covers for cockpit radio and guards for potake-off shafts were manufactured by company using 3D printer" (Kharpal, 2014).

\section{Food Printing}

Application of 3D printing technology to food printing gives instantaneous automatic and reproducible process which can be customized also. By the use of food printing based on robotic layer permits the digitalization of the recipe which can be saved for future use to prepare it again in a reproducible manner. It can also aid in customizing the size, shape and type of decoration of food. Choc Edge is the first company to create the Choc Creator - a commercial 3D chocolate printer which has a nozzle through which the melted chocolate can be dispensed into any pattern and shape depending on the customer's choice (Pallottino et al., 2016).

\section{Healthcare}

\section{(i) Artificial Tissue Models}

More than seven kinds of 3D bioprinters are accessible in the markets which are utilized by research and development users. These printers work mainly on the principles of droplet and extrusion bioprinting. The droplet bioprinter also known as drop by drop or drop on demand bioprinting is such initial techniques for fabrication of tissues and organs. Non contact reprographic approach is used in this process where the cells are enclosed in the droplet which is then printed layer by layer (Moon et al., 2016). Based on the principles of bioprinting, it is of two types: Thermal or Peizoelectric (acoustic). Thermal droplet bioprinting works by producing hotness inside the bio-ink compartment resulting into the spurts of pressure that emits picoliter capacity of condensations at the aperture of the imprinter. The piezoelectric droplet bioprinter needs a 
piezoelectric gemstone positioner that should create the auditory waves inside the bio-ink compartment to emit the droplets through the aperture of the printer (Gurkan et al., 2014).

The Extrusion Bioprinting consists of an ejector or manifold ejector apportions system along with a self regulating three axis (x-y-z) robotic juncture managed by stage regulator. This technique uses a dispenser (mechanical or pneumatic) which is utilized for accumulating the bio-ink with suspending cells over a fabricating substance. Here the viscous bio-ink ejects in a continuous filament rather than in a droplet form (Ferris et al., 2013).

The biomaterials utilized in this process may be natural (e.g. collagen, fibrin, hydroxyapatite, hyaluronic acid and alginate) or synthetic (e.g. Polyglycolide (PGA), Polylactide (PLA), Polyethylene Glycol (PEG) and Poly lactic-coglycolide (PLGA)) (Enam and Jin, 2015).

\section{(ii) Musculoskeletal Bioengineering}

The cortical tissues of bone are highly mineralized while the inner ones consist of highly pervious and vascularized cancellous tissue. The major role of cortical region is to bear load and provide support. Small defects in bone are very easily healed naturally but larger defects require some superficial aid. There are several confronts with the tissue engineered arenas regarding the diffusion of oxygen and nutrition. While designing the scaffold, its porosity should be such that it permits the passage of nutrients within the scaffold, foster the propagation of cells, assists in creation of fresh blood vessels and aid in removal of waste material. In order to provide a suitable cellular microenvironment and an apt mechanical strength, there should be a proper balance between pore sizes and pore distribution. Autograft bone provided the most satisfactory alternative for bone tissue replacement but unavailability of usable tissue supple is the greatest provocation particularly for patients affected by large-scale injury especially in craniomaxillofacial region (Calvert et al., 2003).

The extracellular region of human bone is composed of collagen, fibronectin, osteopontin, hydroxyl-apatite, water and few other organic and inorganic compounds. Nanohydroxyapatite - nHA is an inorganic compound which constitutes about $70 \%$ of bone matrix (Temple et al., 2014). nHA exhibits a magnificent osteoconductivity, cytocompatibility, bioactivity and capability of being simply contrived in a lab site. It can be amalgamated into the substance either before fusing or crosslinking (if dealing with powders, hydrogels or other fluid substances) or after printing (if solid polymers are involved). Calcium phosphate and tricalcium phosphate are some other substances apart from nHA which can enhance osteogenesis (Cui et al., 2016). 3D printing has bestowed the several vascularized bone constructs which can themselves regulate the osteogenic and angiogenic growth factor delivery. Even the biomimetic vacularized bone constructs have been fabricated.

\section{(iii) Brain Modelling}

Due to complexity in structure of brain, it is a great challenge to fabricate the in-vitro model of brain as it is very difficult to manufacture the 3D cell loaded parts in a layered layout. Apart from normal casting methods, the 3D printing of brain tissue has been done by utilizing PDMS (Plant Design Management System), micro chambers, silk scaffolds and microfluidics. But the drawback with the technique was that they could not create the replica of complex in vitro structures and patterning the neuronal cells after 3D printing is also a great provocation. To fabricate the exact 3D brain construct biomaterials and biofabrication play a very important role. The biomaterial should be easily abdicable, should allow cells survival and proliferation and should also assist in proper functioning of o neurons. The synthetic Extracellular Matrix 
(ECM) is created by encapsulation of the dissociated cells into the biomaterial scaffolds. Few hydrogels have exhibited the characteristics of nutrient permeability, degradability, biocompatibility and structural stability due to which they have been used as standard ECM (Khaing et al., 2014). Various research investigations have been carried out to create the 3D brain models. A contemporary research investigation has utilized an extrusion 3D bioprinter to fabricate separate coatings of predominant neural cells enclosed in a natural hydrogel. In this study, a multilayered 3D structure was constructed using gellan gum (a polysachharide produced from fermentation by Pseudomonas elodea). After culturing for five days, it was shown by Confocal microscopy that the printed cells could form the 3D neural networks. In another study, the two neural cells of adult rats (retinal glia cells and retinal ganglion cells) were patterned using piezoelectric droplet bioprinter (Lorber et al., 2014). There were no noteworthy variances in terms of cell viability and neurite extension between the 3D printed and natural control cells. Recently BAL (Bioacoustic Leviation Assembly) concept was developed to construct 3D brain structures. This technique uses the robust aural waves to thrust atoms from all ways and grasp them in the central air. It is a rapid, simple and biocompatible process or bioengineering the multilayer tissue models (Bouyer et al., 2015).

\section{(iv) Bronchial Tree Model}

3D replicas are beneficial devices to concoct for thoracic resection, especially the bronchial stenting. In past few years, there has been an upsurge in the figure of victims of lung cancer due to which more cases of pulmonary segmentectomy are being observed. The challenge faced here is the difficulty in identification of the correct bronchus during surgery. To overcome such types of situations, a 3D model of bronchi was prepared and investigated for determining the correct bronchus to be transected before surgery. The replica could easily be moved through the natural bronchus as it was prepared from a soft material. Thus such simulations can be utilized by surgeons during pulmonary segmentectomy to identify the correct bronchus (Matsumoto et al., 2018).

\section{Cardiovascular Diseases}

3D printing of heart is also useful for detecting valvular heart disease and for arranging intersection and invasive events. In case of aortic stenosis, 3D printed replicas have helped in elucidating the structure of aorta comprising root morphology, aortic valve area, distance to coronary arteries and calcium distribution. The hemodynamics across the aortic valve has been estimated by the functional 3D printed prototypes (Hernandez-Enriquez et al., 2017). They have also helped in scheduling operating events for organizational irregularities in the left ventricle such as septal myectomy in individuals with hypertrophic obstructive cardiomyopathy and resection of left ventricular aneurysms (Bartel et al., 2017).

In a study, the myocardial infarction was first surgically induced in a mouse and then the bioprinted patch infused with progenitor cells was inserted into the body of mouse. It was found that the bioprinted patch was able to increase vascularity and also enhanced the cardiac function (Gao et al., 2017). Implantable 3D bioprinted valves are being designed using hydrogels that imitate the environment of extracellular matrix and encourage independent proliferation of cells and confront the mechanical stress. 3D printed models of heart provide a very effective tool in educating medical and nursing students. They also help in enhancing the communication and understanding of the patients which are very beneficial for them in decision making (Sabbagh et al., 2018).

\section{(vi) Tissue Engineering of Skin}

The natural or artificial substitutes for human skin designed in laboratories are known as artificial skins. Skin substitutes are a variety of materials that aid in wound closure which may be either permanent or temporary. An ideal skin ancillary 
should be able to combat infection, prevent loss of water and resist shear forces, durable, cost effective, easy to manufacture, store and use (Shores et al., 2007).

The two basic strategies used for tissue engineering of skin are (i) Bottom-up approach and (ii) Top-down approach. The bottom-up technique involves the usage of cell laden hydrogels, cell-sheets or cell-aggregates to form tissue building blocks which are finally assembled to manufacture engineered tissues. The top-down method requires a porous scaffold where the cells can be cultured, grown and proliferated so that they can migrate over the scaffold and form extra cellular matrix while scaffolds encounter the biodegradation so that finally a fully grown tissue can be obtained. The skin substitutes are basically categorized into three classes: Class I: Temporary impervious dressing's e.g. biological dressing substitute; Class II: Single layer durable skin Substitute's e.g. cultured epithelial autograph; Class III: Composite skin substitute e.g. dermal regeneration template (Bártolo et al., 2011).

The basic steps in 3D bioprinting: pre treating, bioprinting and post production. Firstly the injured tissue is scanned by CT-scan (Computed Tomography), x-ray or MRI (Magnetic Resonance Imaging). The imaging should be such that it resolves any of the aesthetic issue otherwise the skin produced may not be of the similar colour as that of the patient's. Thus, usually 2D sketches on picture printouts are used to target the facial aesthetic features. A hardware independent web-based application has been proposed by Oliveira-santos et al., which utilize 2D digital photos to make 3D portrayal of victim's skin for aiming the aesthetic procedures (Oliveira-Santos et al., 2013).

Gelatin, collagen, chitosan and silk fibroin are mostly used natural biopolymers whereas PCL, PLA, PLGA and PLLA are the most common synthetic polymers for skin bioengineering. Electrospinning is the technique used to create composite biopolymers utilizing one natural and synthetic polymer. These then act as the scaffold for skin tissue engineering. Selection of suitable cells for regeneration is the most important factor for the triumph of tissue engineering process. Keratinocytes are usually used for this purpose as they can be easily cultured, propagated and maintained at laboratory conditions. Although 3D bioprinting is a boon to the grafting technique yet it suffers from some disadvantages like long healing time and high cost (Norouzi et al., 2015).

\section{(vii) Plastic Surgery}

Even though 3D printing is widely used in clinical practice yet it does not find a frequent clinical bedside application because the medical practitioners think that the technique is very sophisticated and thus an external company is hired for this task. Perforator Flap Surgery is normally used for reconstructing the post trauma large soft tissue defects. A current research investigation involved the perforator flap based reconstruction for a soft tissue ankle defect. First the CTA of the recipient site i.e., lower limbs and the donor site i.e., the forearms was carried out and the DICOM data was converted into a CAD file. Then, the 3D image of regular contralateral ankle was taken and was overlaid over the picture of pathological side. A 'reverse' model depicting the wound defect was created using the Magics software. This provided the surgeon with preoperative support describing the length, depth and width of the free flap that was required to completely conceal the defect (Chae et al., 2014).

The technique has also been utilized for reconstructing the sacral wound defect occurring after oncologic resection and for preoperative planning for post-mastectomy breast asymmetry. It is very difficult to interpret the vascular framework of the perforators and their association with the regional anatomical structures. To overcome this difficulty, CTA has been successfully used. A recent study by Gillis and Morris depicted a replica of internal mammary artery 
perforators and adjacent ribs constructed by binder jet 3D printing device. 3D printers are now also utilized for bony mapping of wrist, hand, forearm, maxillofacial surgery neurosurgery and orthopedic surgery (Gillis and Morris, 2014).

(viii) Development of Dosage Forms

Different 3D printing procedures are utilized for fabricating a diversity of dosage forms intended for a particular use carrying specific Active Pharmaceutical Ingredients (API's) and excipients. The powder based 3D printing technique has been utilized for preparing resorbable devices which are novel dosage form exhibiting controlled release profile, multi drug implants for bone tuberculosis, cubic core shell structures, orodispersible dosage forms and delayed release, fast disintegrating and controlled release tablets. Polymeric structures for chronic inflammatory diseases, polypil for cardiovascular treatment with 5 drugs incorporated in a single pill in distinct instantaneous and extended release chambers, bilayer tablets for respiratory tract infections and tablets for multiple chambers containing sustained release compartments for glipizide and nifedipine and an osmotic pump for captopril have been fabricated using Extrusion based 3D printing (Khaled et al., 2015).

Different types of tablets such as controlled release, modified release, extended release capsular devices with novel erodible capsule shells, circular discs and reservoir matrix structures are fabricated by Fused Deposition Modelling 3D printing. The advancements in development of dosage forms with 3D printing has numerous advantages like personalized dose, mini dispensar component, new structures \& designs and accelerated disintegration. Despite of these advantages, there are some limitations such as non-reproducibility, imperfections in finished product and regulatory challenges.

\section{APPLICATIONS OF 4D PRINTING}

\section{(1) Aeronautics and Robotics}

The modern air aeration bays are invariable while the air drift alters with the promptness of airplane. To overcome this problem, a collaboration of MIT Research Scientist Skylar Tibbits and Emerging Technology and Concept team from Airbus created new air inlet which could automatically regulate to regulate the flow of air. 4D printing will permit the manufacture of receptive and highly sensitive parts with more advanced, pliable and powerful potential to carry out the complicated work effectively. The origami robots which are reconfigurable having the potential of folding themselves into capricious shapes and dragging away themselves have been established by a team of researchers at MIT and Harvard University by completely using the printable parts (Hardesty, 2014).

\section{(2) Military}

The programmable material is used to develop 3D printed spare parts to create full building with all the essential facilities like electricity, plumbing etc. With 4D technology, the shape of the materials can be altered which can also help the military personnel, equipments and installations in completely disguising themselves. 4D printing can also help in manufacturing the coating materials for automobiles that would make them more resistant to environment (Laskar, 2017).

\section{Furniture and House Appliances}

The furniture parts are available now which have made the assembling, disassembling and moving from one place to another very simple, comfortable, economical and time saving. 


\section{(4) Fashion}

It is a very fascinating idea to have clothes that adjust according to the shape of the body and alter themselves according to the environmental conditions. 4D printed wearable suits have been developed by Massachusetts based design studio Nervous System which consists of exclusive intertwining constituent and the costume responds to the body of the person wearing it (Designboom. 2014). Currently, not much data is available regarding the printing of dresses by 4D, but certainly in coming future, new softwares, programmable materials and design tools may provide such wearable which one would have heard only in science fictions.

\section{Healthcare}

\section{(i) Tissue Engineering}

For successful tissue engineering it is very essential to fabricate the functional blood vessels because these are the structures that are responsible for supplying oxygen and nutrition and also for removing the waste products. With 4D bioprinting it has become possible to fabricate the biomimetic blood vessels in vitro. Vasculature can be created by 4D bioprinting either by encapsulating the diverse kinds of cells to form complex duct like formations in existence of water or by utilizing the benefit of regular self organization potential of the cells. Mass diffusion can only occur when the supplying tissues are at a distance of 100-200nm, thus limiting the tissue to this size in absence of vascular transfer (Jain et al., 2005). The solution to this problem has been given by layer-by-layer 4D bioprinting where the cells are mixed with hydrogels which can then be printed into tube like structures resembling the blood vessels and activated by maturation factors to help the vacular cells to rapidly multiply and form vascularization According to Hong, et al. (2013), multiple cell types, including fibroblasts, MSCs, and ECs, were patterned in a hydrogel through a 4D printing system (Hong et al., 2013).

Villar et al., (2013) has reported the formation of stable bilayers by lipid-coated aqueous droplets printed in oil (Villar $e t$ al., 2013). The vascular tubes like structures have also been assembled by using bioprinted agarose rods through cell fusion and maturation. The blood vessels with discrete geometries have also been fabricated. Pati et al., has reported that "4D bioprinted polymeric bone graft has been created by printing the grid pattern and then coating with human nasal terbinate tissue derived MSCs (hTMSCs) for graft mineralization. After a brief culture period, the printed bone tissue graft became mature, and the decellularized graft was investigated both in vitro and in vivo and found to have improved osteoinductive and osteoconductive" (Pati et al., 2015).

\section{(ii) Drug Delivery}

The encapsulation and release of drugs can also be controlled in a programmable fashion by utilizing the self folding or unfolding components in the formulation, such as., printing 'multisomes' (small oil droplets encapsulating the aqueous droplets) in water. By any alteration in the $\mathrm{pH}$ or temperature of the nearby setting, the content of the droplets can be released. A research investigation by $\mathrm{He}$ et al., used the differentially swelling polymeric hydrogel to create self-folding procedures, allowing the direct encapsulation and discharge of medicine. The formulation consisted of a mucoadhesive coating containing drugs and two deposits each with a different swelling ratio. First layer was made up of $\mathrm{pH}$ sensitive hydrogel deposit consisting of crosslinked PMMA (poly (methyacrylic acid) which swells on coming into interaction with body fluids. The other coating was comprised of non swelling PHEMA -poly (hydroxyethyl methacrylate) (He et al., 2006). 


\section{APPLICATIONS OF 5D PRINTING}

\section{(1) In Surgery}

3D anatomic models for multifaceted resection cases ameliorate the knowledge of the patients and assist in effective scheduling for the surgery. The 5D printing method includes statistics utilized for creating 3D replica in accumulation to information concerning tumor reaction and anatomical action to initiation remedy. According to this mentioned investigation of Gillaspie et al., "The dimensions of 5D printing are height (y axis), width (x axis), depth (z axis), change in tumor size (change in computed tomography [CT] measured dimensions) and physiology (change in positron emission tomography [PET]-measured 18F-fluorodeoxyglucose [FDG] avidity). A patient presenting with a complex thoracic tumor was selected for 5D printing. 3D and 5D models were prepared to allow surgical teams to directly evaluate and compare the added benefits of information provided by printing in 5 dimensions. Printing 5D models in patients with complex thoracic pathology facilitates surgical planning, selecting margins for resection, anticipating potential difficulties, teaching for learners, and education for patients" (Gillaspie et al., 2016).

\section{(2) In Nanomedicine}

The additive manufacturing has provided a novel opportunity for association amid medical and engineering field. Foresti $e t$ $a l$., presented "method based on rapid freeze prototyping (RFP), 3Dprinter, reconstruction cutting, nano dry formulation, fast freeze gelation, disinfection and partial processes for the 5D digital models functionalisation". They detailed the "highresolution computer tomography scan derived from a complex human peripheral artery" and "reconstructed the 3D model of the vessel in order to obtain and verify the additive manufacturing processes". Thus, they were able to manufacture "5D high resolution self-dissolving devices incorporating nanoparticles with the perspective to apply the method to the personalised medicine" (Foresti et al., 2020).

\section{CONCLUSIONS}

The emerging additive manufacturing by 3D printing finds various applications in Education, Architecture, Marine, Aerospace, Robotics, Consumer Goods, textiles, Automotives, Industrial Goods, Military, Food Printing and Healthcare (artificial tissue models, musculoskeletal bioengineering, brain modeling, bronchial tree model, cardiovascular diseases, tissue engineering of skin, plastic surgery and development of dosage forms). Although 3D printing provides numerous benefits like customization of the existing designs, easy availability, low cost, efficient manufacturing process and quality product yet there are a few disadvantages such as longer production time, complicated software, requirement of post processing, limitations in material selection and requirement of controlled environment.

4D bioprinting came into existence to enhance the applicability of 3D printing. 4D printing also considers that how the living tissues develop gradually with time after being printed based on deformation of materials and on maturation of engineered tissue constructs. Although, this emerging technology also finds numerous applications including tissue engineering and drug delivery yet it bears some shortcomings like requirement of expensive smart materials and hardware, controlled environment etc.

$5 \mathrm{D}$ printing is providing the additional benefits to the $3 \mathrm{D}$ printed objects in terms of their enhanced strength and superior design. The technique can be used in manufacturing car parts, designing jewellery, educating the patients, planning the surgeries and for preparing customized nanomedicine. 5D printing might help 3D printing to move from laboratory research to bedside and thus attaining the status of translational science. 


\section{ACKNOWLEDGEMENTS}

The authors are thankful to KIET School of Pharmacy Library, Ghaziabad and NISCAIR Library, New Delhi for providing the literature and Principal, KIET School of Pharmacy and Head of Department of Electronics and Communication Engineering, ABES Engineering College, Ghaziabad for their constant support and encouragement.

\section{CONFLICTS OF INTEREST: None}

\section{REFERENCES}

13. Bartel T, Rivard A, Jimenez A, Mestres CA, Muller S (2017). Medical three-dimensional printing opens up new opportunities in cardiology and cardiac surgery. Eur Heart J., 38.

14. Bártolo PJ, Domingos M, Patrício T, Cometa S, Mironov V (2011). Biofabrication strategies for tissue engineering Advances on Modeling in Tissue Engineering (Amsterdam: Springer), 137-76.

15. Bouyer C, Chen P, Guven S, Demirtas T, Nieland T, Padilla F, Demirci U (2015). A bio-acoustic levitational (BAL) assembly method for engineering of multilayered, three-dimensional brain-like constructs, using human embryonic stem cells derived neuro-progenitors. Adv. Mater., 67, 264-273. (doi:10.1002/adma.201503916).

16. Calvert JW, Weiss LE, Sundine MJ (2003). New frontiers in bone tissue engineering. Clin Plast Surg, 30(4), 641.

17. Chae MP, Lin F, Spychal RT, Hunter-Smith DJ, Rozen WM (2014). 3D-printed haptic "reverse" models for preoperative planning in soft tissue reconstruction: a case report. Microsurgery, 35(2), 148-152.

18. Chhaya MP, Poh PS, Balmayor ER, Van Griensven M, Schantz JT, Hutmacher DW (2015). Additive manufacturing in biomedical sciences and the need for definitions and norms. Expert Rev Med Devices, 12, 537-543.

19. Chung P, Heller JA, Etemadi M, Ottoson PE, Liu JA, et al. (2014). Rapid and low-cost prototyping of medical devices using $3 D$ printed molds for liquid injection molding. J Vis Exp, 88, e51745.

20. Cnet (2015). World's first 3D printed apartment building constructed in China. Retrieved June 2020, from https://www.cnet.com/au/news/worlds-first-3d-printed-apartment-building-constructed-in-china/

21. Cui H, Zhu W, Holmes B, Zhang LG (2016). Biologically inspired smart release system based on $3 D$ bioprinted perfused scaffold for vascularized tissue regeneration. Advanced Science, 3(8), 1600058.

22. Designboom. 2014. Retrieved June 2020, from http://www.designboom.com/technology/nervous-system-kinematics-4dprintdress-created-from-body-scans/

23. Enam S, Jin S (2015). 2 Substrates for clinical applicability of stem cells. World J Stem Cells, 7, 243.

24. Ferris CJ, Gilmore KG, Wallace GG (2013). Biofabrication: an overview of the approaches used for printing of living cells. Appl Microbiol Biotechnol, 97, 4243-4258.

25. Fogliatto, Fogliatto FS, Silveira GJCD, Borenstein D (2012). The mass customization decade: an updated review of the literature. Int J Prod Econ, 138 (1), 14-25.

26. Foresti $R$, Rossi S, Pinelli $S$ et al., (2020). In vivo vascular application via ultrafast bioprinting for future 5D personalized nanomedicine, Scientific Reports, 10, 3205, 1-13.

27. Gao B, Yang Q, Zhao X, Jin G, Ma Y, Xu F (2016). 4D Bioprinting for Biomedical Applications. Trends in Biotechnology 34, 746-756.

28. Gao L, Kupfer ME, Jung JP, Yang L, Zhang P, Da Sie Y, et al. (2017). Myocardial tissue engineering with cells derived from 
humaninduced pluripotent stem cells and a native-like, high-resolution, 3-dimensionally printed scaffold. Circ Res, 120, 131825.

29. Gillaspie EA, Matsumoto JS, Morris NE et al. (2016). From 3-Dimensional printing to 5-Dimensional printing enhancing thoracic surgical planning and resection of complex tumors, Annals of Thoracic Surgery, 101, 1958-62.

30. Gillis JA, Morris SF (2014). Three-dimensional printing of perforator vascular anatomy. Plast Reconstr Surg, 133.

31. Goyanes A, Buanz AB, Hatton GB, Gaisford S, Basit AW (2014). 3D printing of modified-release aminosalicylate (4-ASA and 5-ASA) tablets. Eur J Pharm Biopharm, 89, 157-62.

32. Gurkan UA, Assal RA, Yildiz SE, Sung Y, Trachtenberg AJ, Kuo WP et al. (2014). Engineering anisotropic biomimetic fibrocartilage microenvironment by bioprinting mesenchymalstem cells in nanoliter gel droplets. Mol Pharmaceutics, 11(7), $2151-2159$.

33. Hardesty, L. MIT News. 2014. Retrieved June 2020, from http://news.mit.edu/2014/mobile-folding-robots-0807

34. He HY, Guan J, Lee JL (2006). An oral delivery device based on self-folding hydrogels. J. Control. Release, 110, $339-346$. (doi:10.1016/j.jconrel.2005.10.017).

35. Hernandez-Enriquez M, Brugaletta S, Andreu D, Macia-Munoz G, Castrejon-SubiraM, Fernandez-Suelves S, et al. (2017). Three-dimensional printing of an aortic model for transcatheter aortic valve implantation: possible clinical applications, Int $J$ Cardiovasc Imaging, 33, 283-5.

36. Hong S, Song SJ, Lee JY, Jang H, Choi J, Sun K, Park Y 2013. Cellular behavior in micropatterned hydro- gels by bioprinting system depended on the cell types and cellular interaction. J. Biosci. Bioeng., 116, 224-230. (doi: 10.1016/j.jbiosc.2013.02.011)

37. Ikegami T, Maehara Y (2013). TRANSPLANTATION 3D printing of the liver in living donor liver transplantation. Nat. Rev. Gastro Hepat., 10, 697.

38. Jain RK, Au P, Tam J, Duda DG, Fukumura D (2005). Engineering vascularized tissue. Nat. Bio-technol, 23, $821-823$ (doi: 10.1038/nbt0705-821)

39. Khaing ZZ, Thomas RC, Geissler SA, Schmidt CE. Advanced biomaterials for repairing the nervous system: what can hydrogels do for the brain? Mater. Today, 2014, 17: 332-340.

40. Khaled SA, Burley JC, Alexander MR, Yang J, Roberts CJ (2015). 3D printing of five-in-one dose combination polypill with defined immediate and sustained release profiles. J Control Release, 217, 308-14.

41. Kharpal A (2014). CNBC. Retrieved June 2020, from http://www.cnbc.com/2014/01/06/fighter-jet-with-3d-printed-parts-fliesforfirst-time.html

42. Korger M, Bergschneider J, Lutz M, Mahltig B, Finsterbusch K, Rabe M (2016). Possible Applications of 3D Printing Technology on Textile Substrates. IOP Confr Series: Materials Science and Engineering, 141, 1-5.

43. Kumar P, Roy S, Hedge H, Bharti S, Kumar M (2019). 4D and 5D Printing: Healthcare NewEdge. Chapter 8, 3D Printing in nanomedicine, 143.

44. Laskar, $N$ (2018). The emergence of $4 D$ printing; What's next? 2017. Retrieved June 2020, from https://www.linkedin.com/pulse/emergence-4d-printing-whats-nextnadzia-laskar

45. Lorber B, Hsiao WK, Hutchings IM, Martin KR. Adult rat retinal ganglion cells and glia can be printed by piezoelectric inkjet printing. Biofabrication. 2014; 6: 015001. 
46. Matsumoto K, Yamasaki N, Tsuchiya T, Miyazaki T, Kamohara R, Hatachi G, Matsuo N, Nagayasu T (2018). Threedimensional (3D) bronchial tree model for bronchial resection with pulmonary segmentectomy. J Thorac Dis, 10(3), E179E182. (doi: 10.21037/jtd.2018.02.04)

47. MALUR, PRASHANTH G., and Nandini Lakshmikantha. "An Exploratory Study on the Opportunities in Visual Media \& the Need to Up Skill Academic Programmes." International Journal for Communication and Media Studies (2019).

48. Miller JS, Stevens KR, Yang MT, Baker BM, Nguyen DH, Cohen DM, et al. (2012). Rapid casting of patterned vascular networks for perfusable engineered three-dimensional tissues. Nat. Mater., 11, 768-774 (doi: 10.1038/nmat3357).

49. Mohammad JS (2016). Applications of 3D printing technology in Oceanography. Methods in Oceanography, 17, $97-117$.

50. Moon S, Ceyhan E, Gurkan UA, Demirci U, Borlongan CV (2016). Statistical modeling of single target cell encapsulation. PLoS One, e21580.

51. Norouzi M, Boroujeni SM, Omidvarkordshouli N, Soleimani M (2015). Advances in skin regeneration: application of electrospun scaffolds. Adv. Healthcare Mat., 4, 1114-1133.

52. Oliveira-Santos T, Baumberger C, Constantinescu M, Olariu R, Nolte LP, Alaraibi S, Reyes M, et al. (2013). 3D face reconstruction from $2 d$ pictures: first results of a web-based computer aided system for aesthetic procedures. Ann. Biomed. Eng., 41, 952-66. (doi: 10.1007/s10439-013-0744-3)

53. Pallottino F, Menesatti P, Hakol L, Costa C, Antonucci F, Figorilli S, Seisto A (2016). Printing on Food or Food Printing: a Review. Food Bioprocess Technol,9, 725-733.

54. Pati F, Shim JH, Lee JS, Cho DW (2013). 3D printing of cell-laden constructs for heterogeneous tissue regeneration. MFGLET, 1(1), 49-53.

55. Pati F, Song TH, Rijal G, Jang J, Kim SW, Cho DW (2015). Ornamenting 3D printed scaffolds with cell-laid, 230-241.

56. Pattni $V$ (2016). Honda has 3D-printed an electri shortbread delivery van. Retrieved from BBC Top Gear: https://www.topgear.com/carnews/electric/honda-has-3d-printed-electric-shortbread-delivery-van

57. Reddy PR, Devi PA (2018). Review on the advancements of Additive manufacturing- $4 D$ and 5D printing,.International Journal of Mechanical and Production Engineering Research and Development, 8(4), 397-402.

58. Reddy, P. RAVINDER, and P. ANJANI Devi. "Review on the advancements of additive manufacturing $4 D$ and $5 D$ printing." Int J Mech Prod Eng Res Dev 8.4 (2018): 397-402.

59. Sabbagh AE, Eleid MF, Al-Hijji M, Anavekar NS, Holmes DR, Nkomo VT, et al. (2018). The Various Applications of $3 D$ Printing in Cardiovascular Diseases. Current Cardiology Reports, 20, 47.

60. Sculpteo. Mastering Aeronautics and Aerospace prototyping. 2016; Retrieved June 2020, from https://www.sculpteo.com/en/applications/aeronautics-and-aerospacel

61. Shores JT, Gabriel A, Gupta S (2007). Skin substitutes and alternatives: a review Adv. Skin Wound Care, 20, 493-508.

62. Stanton MM, Paredesa CT, Sánchez S (2015). Applications of three-dimensional (3D) printing for microswimmers and biohybrid robotics. Lab on a Chip, 15, 1634-1637.

63. ALPHONSE, MATHEW, R. Ramesh Kumar, and M. Senthil Kumar. "Recent trends and advancements in the field of Micro electrical and mechanical systems (MEMS) technology." International Journal of Mechanical and Production Engineering Research and Development (IJMPERD) ISSN (P): 2249-6890; ISSN (E): 2249-8001 Vol 7: 479-488.

64. SINGH, DDEV, and GOPI RAHUL. "DESIGN AND DEVELOPMENT OF CARTESIAN CO-ORDINATE BASED 3D 
PRINTER." Power 12: 10A.

65. Suresh, Ganzi, et al. "Electro chemical behaviour of lensTM deposited Co-Cr-W alloy for bio-medical applications." Int. J. Mech. Prod. Eng. Res. Dev 2018 (2018): 41-52.

66. Technologies J (2011). Retrieved December 20 2018, from https://www.youtube.com/watch? v=7cm_b2ExOlI

67. Technologies J (2016) Aerospace. Retrieved June 2020, from http://www.javelin-tech.com/3d-printer/industry/aerospace/

68. Temple JP, Hutton DL, Hung BP, Huri PY, Cook CA, Kondragunta R, et al. (2014), Engineering anatomically shaped vascularized bone grafts with hASCs and 3Dprinted PCL scaffolds. J Biomed Mater Res A, 102(12), 4317-4325.

69. Villar G, Graham AD, Bayley H (2013). A tissue-like printed material. Science. 340, 48-52. ( doi: 10.1126/science.1229495)

70. Water JJ, Bohr A, Boetker J, Aho J, Sandler N, Nielsen HM, et al. (2015). Three-dimensional printing of drug-eluting implants: preparation of an antimicrobial polylactide feedstock material. J Pharm Sci, 104(3), 1099-107.

71. Weber S. 3D printing of anatomical heart models for surgical planning in cardiac surgery (2007). Int. J. Comput. Assist. Radiol. Surg., 2, S160-S180.

72. Xu F, Celli J, Rizvi I, Moon S, Hasan T, Demirci U (2011). A three-dimensional in vitro ovarian cancer coculture model using a high-throughput cell patterning platform. Biotechnol J, 6, 204-212.

73. Yang WG, Lu H, Huang WM, Qi H, WuXL, Sun KY (2014). Advanced shape memory technology to reshape product design, manufacturing and recycling. Polymers, 6(8), 2287-2308. 